\title{
Characterization of Silver Nanoparticles Synthesized using Chemical Method and its Antibacterial Property
}

\author{
Veeraswamy Thiruvengadam ${ }^{1 \mathbb{D}}$, Ankur V. Bansod ${ }^{2, *}$ (D) \\ 1 Department of Mechanical Engineering, Vel Tech Rangarajan Dr.Sagunthala R\&D Institute of Science and Technology, Avadi, \\ Chennai, India; thiru_vengadam73@yahoo.co.in; \\ 2 Department of Mechanical Engineering, Vel Tech Rangarajan Dr.Sagunthala R\&D Institute of Science and Technology, Avadi, \\ Chennai, India; ankur.1754@gmail.com; \\ * Correspondence: ankur.1754@gmail.com;
}

Scopus Author ID 57190381539

Received: 9.04.2020; Revised: 28.05.2020; Accepted: 1.06.2020; Published: 7.06.2020

\begin{abstract}
Metal nanoparticles are gaining importance nowadays in nanoscience. The nanoparticle had better physical and chemical properties compared with solid particles due to their large surface area. The silver nanoparticles are employed mostly in medical and electrical applications having outstanding conductivity and antimicrobial activity. In the present investigation, $\mathrm{NaBH} 4$ and ethanol were used as a reductant and stabilizer agent from silver nitrate salt as a precursor. The silver nanoparticles obtained were characterized using Fourier-transform infrared spectroscopy (FT-IR), X-Ray diffraction (XRD) and high-resolution transmission electron microscopy (HRTEM) to determine their morphology and size. In XRD analysis, the average particle size was found to be $18.31 \mathrm{~nm}$. The TEM analysis shows crystalline morphology with a face-centered cubic structure. The antibacterial activity was tested against two bacterial cultures, namely Bacillus subtilis and Pseudomonas aeruginosa. The inhibition zones of $19 \mathrm{~mm}$ and $17 \mathrm{~mm}$ were observed against Bacillus subtilis and Pseudomonas aeruginosa, respectively.
\end{abstract}

Keywords: Chemical synthesis; Silver nanoparticle; Antibacterial; $\mathrm{NaBH}_{4}$.

(C) 2020 by the authors. This article is an open-access article distributed under the terms and conditions of the Creative Commons Attribution (CC BY) license (https://creativecommons.org/licenses/by/4.0/).

\section{Introduction}

The development of nanoparticle in recent years had evolved various methods to synthesize nanoparticle of various sizes and shapes of the metal. Metal nanoparticles possess unique chemical and physical properties from their bulk materials due to their high surface area to volume ratio [1].

In recent medical applications, the use of metal nanoparticles has made its standard. It has been observed that the use of silver nanoparticles is extensively used for medical purposes due to its better chemical stability and good antimicrobial activity [2]. The silver nanoparticles were well known for the antibacterial property, which makes use of surgical prostheses and dental implants. In general, there are two approaches employed in synthesis nanoparticles, first is the top-down approach (Physical methods), and second is the bottom-down (chemical and biological methods) [3].

The physical method employs machining and etching to produce nanoscale structures whereas, other method employs chemicals such as sodium borohydride, ethanol, ethylene glycol, etc. as reducing agents [4]. The chemical method is commonly used for producing silver particles. This is because of the simple equipment needed and convenient to operate. Badi'ah 
et al. synthesized silver nanoparticles using $\mathrm{AgNO}_{3}$ as a source of $\mathrm{Ag}$ and $\mathrm{NaBH}_{4}$ as a reducing agent. They observed the change of color in the solution, which confirms the formation of the silver particle [5].

The first phase for the formation of particles involves the reduction of $\mathrm{Ag}^{+}$to $\mathrm{Ag}^{-}$atoms takes place forming clusters. In the second phase, the clusters coalesce to form nanoparticles of 2-3nm. The next phase is the metastable state takes place within 5-10 min maintaining the size. The last phase is the coalescence phase, which results in the formation of AgNPs of an average size of 5-8nm within 30-60 s [6]. Stabilizers are the compound which helps in the favors the formation of silver nanoparticle also helps in preventing it from aggregation [7].

For producing spherical particles, the biological method is useful in some cases despite being cheaper and eco-friendly [8]. Chemical synthesis of silver nanoparticle (AgNPs) was carried out by employing polyvinylpyrrolidone and di-sodium succinate hexahydrate and trisodium citrate dihydrate to form spherical to triangular nanocrystals in 300 seconds of reaction time at room temperature [9]. Sodium borohydride and polyvinylpyrrolidone used to synthesize the AgNPs from the aqueous silver nitrate solution. The morphology of the particle also influences the antimicrobial property.

It was reported that a higher concentration of spherical AgNPs has high antibacterial activity against Escherichia coli bacteria [10]. In another investigation, sodium nitrate was used as a precursor salt with sodium borohydride in talc as a reductant to obtain AgNPs. The particle size of AgNPs was of the range of 7.60nm to $13.11 \mathrm{~nm}$ and spherical shape [4]. The size of the AgNPs makes them good absorbing and scattering of the light particles [11]. TEM images reveal that the molar ratio of $\mathrm{AgNPs} \mathrm{NaBH}_{4} / \mathrm{AgNO}_{3}$, which decides the degree of aggregation.

With the increase of $\mathrm{NaBH}_{4}$ concentration, the aggregation was reduced considerably [12]. Some researchers had reported triangular shape silver particles in their study [13]. The silver nanoparticle has been reported to be the most effective against microbial activities [14]. Many researchers have reported the use of silver and silver nanoparticles in medical applications like medial health care and dental materials [15].

However, many bacteria have developed resistance against most of the medicine, which results in lower efficiency. Hence, in this study, silver nanoparticle was synthesized using sodium borohydride as reductant ethanol as the stabilizer. The antibacterial potential of the AgNPs against the Bacillus subtilis and Pseudomonas aeruginosa was evaluated as there is no report concerning the synthesis of AgNPs followed by antimicrobial activity with the above bacteria.

\section{Materials and Methods}

The chemical synthesis of silver particles was carried out using silver nitrate $\left(\mathrm{AgNO}_{3}\right)$, sodium borohydride $\left(\mathrm{NaBH}_{4}\right)$, and ethanol with analytical grade. Sodium borohydride was used as a reducing agent and ethanol as a stabilizer. To produce silver particles, $500 \mathrm{mg}$ of silver nitrate is dissolved with $20 \mathrm{ml}$ of ethanol and magnetically stirred to obtain a uniform solution. Then $500 \mathrm{mg}$ of sodium borohydride was added drop by drop to this solution. Color change from colorless to black color of the solution implies the formation of AgNPs. The aqueous solution poured in the Petri dish at room temperature and dried to get solid particles. Figure 1 shows photographs of chemical synthesis. Fourier transform infrared spectroscopy (FTIR Spectrophotometer-1 Raffinity, Shimadzu, Japan) studies were performed for analysis of chemical bonding and functional group. X-ray diffraction (XRD, D8 Advance, Bruker) using 
$\mathrm{Cu}-\mathrm{K} \alpha$ radiation was used for the identification of phase transformations of the AgNPs. The XRD pattern was recorded in the $2 \theta$ range between $10^{\circ}$ to $80^{\circ}$ at a scan speed of $2 \% \mathrm{~min}$. The silver nanoparticles film was placed on carbon-coated TEM grids and analyzed by highresolution transmission electron microscopy (ModelFEI-Technai T20 Twin $200 \mathrm{KV}$ instrument). The antimicrobial properties for silver nanoparticles were tested against Bacillus subtilis and Pseudomonas aeruginosa. The disc diffusion method was used to analyze antimicrobial properties. Bacillus subtilis and Pseudomonas aeruginosa, inoculums were prepared by using nutrient broth media. Silver nanoparticle synthesized were placed on sterile discs. Discs were dried aseptically under laminar airflow to remove solvents. Dried discs placed on the surface of culture inoculated Mueller Hinton agar plates and plates incubated at $37^{\circ} \mathrm{C}$ for $24 \mathrm{hr}$. Antibacterial activity was evaluated by using the Himedia zone reader [16].

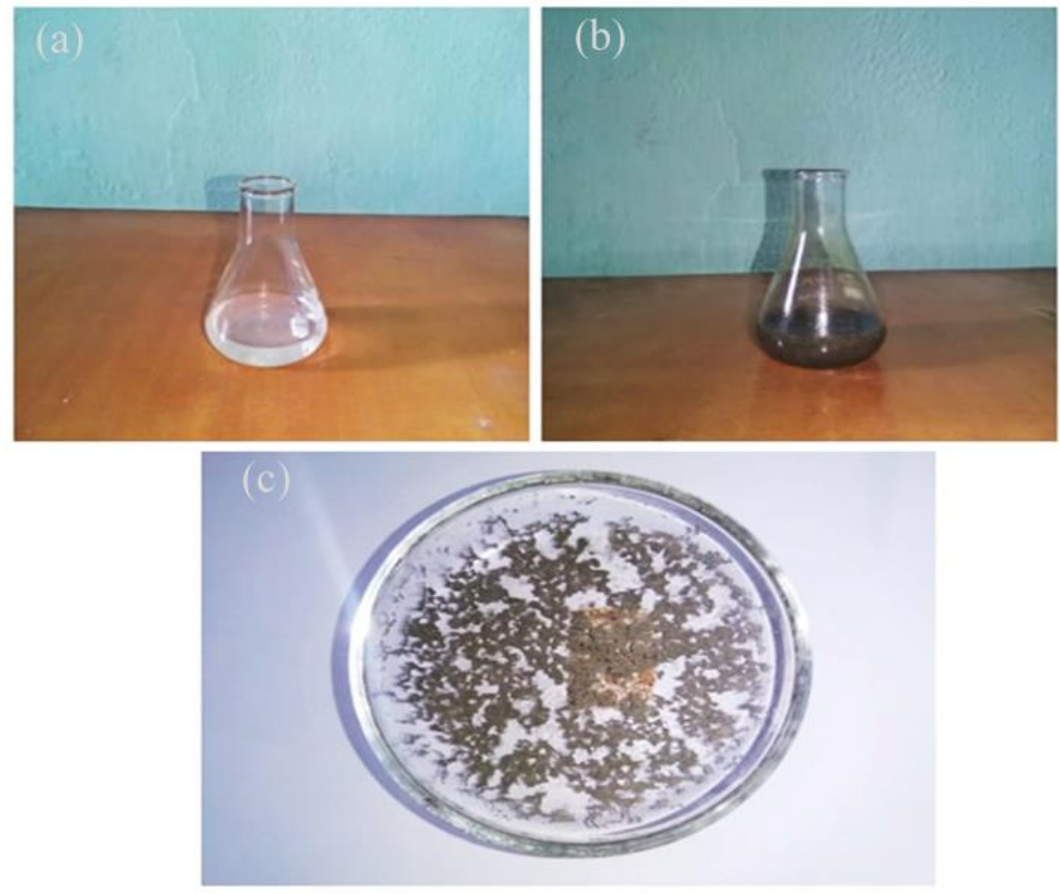

Figure 1. Photograph of chemical synthesis (a) $\mathrm{AgNO}_{3}$ dissolved in ethanol (b) $\mathrm{AgNO}_{3}$ solution after adding sodium borohydride and (c) silver nanoparticles.

\section{Results and Discussion}

\subsection{FTIR.}

The FTIR spectrum shows various functional groups present at different positions, as shown in Figure 2. The peaks in the region between $3490 \mathrm{~cm}-1$ to $2850 \mathrm{~cm}-1$ were assigned to $\mathrm{O}-\mathrm{H}$ stretching of alcohol compounds and aldehyde-C-H- stretching of alkanes. The peaks $1625 \mathrm{~cm}-1$ correspond to C-N stretch vibration medium of arenes, $1379 \mathrm{~cm}-1$ to $1068 \mathrm{~cm}-1$ correspond to primary and secondary amides of N-H (bond) of and -C-N- stretching vibration of amines and peaks between $806 \mathrm{~cm}-1$, and $761 \mathrm{~cm}-1$ were assigned to $\mathrm{O}-\mathrm{H}$ (H-bonded), usually weak bending vibrations of alcohol. After the reaction, the shift in the peak from 3489.23 to $3205.69,1408.04$ to1350.17, 1122.57 to 1068.56 , and 806.25 to 761.88 is indicating that carboxyl, hydroxyl and amide groups may be participating in the process of nanoparticle synthesis[17]. This analysis shows the dual behavior of molecules which may be responsible for the reduction and stabilizing of silver nanoparticle [18]. 


\subsection{X-ray diffraction spectroscopy.}

Figure 3 shows the XRD peaks of the silver nanoparticle. The peaks were observed at $2 \theta$ values of $38.45^{\circ}(\mathrm{Ag} 2 \mathrm{O}), 44.67^{\circ}(\mathrm{Ag} / \mathrm{AgO}), 64^{\circ}(\mathrm{Ag} 2 \mathrm{O}), 77^{\circ}(\mathrm{Ag})$, and $81.88^{\circ}(\mathrm{Ag})$ correspond to Ag (111), (200), (220), (311), and (222). High intensity at $38.45^{\circ}$ reflection indicates that the crystallites are mainly orients in this plane. Dorobantu et al. reported that the formation of $\mathrm{Ag}$ from $\mathrm{AgO}$ is mainly due to lower temperatures below $30^{\circ} \mathrm{C}$ [19]. The reflections are broader, revealing that smaller size of AgNP crystals. The size of crystals ( $t$ ) was determined using the Scherrer formula as given in equation 1 [20].

$$
t=\frac{0.9 \lambda}{\beta \operatorname{Cos} \theta}
$$

Where $\lambda$ is the wavelength of the $X$-ray used (1.5418 $\AA$ ), $\beta$ is the full width at half maximum (FWHM) in radians and $\theta$ is the angle of the reflection. Crystalline sizes calculated, and the values are listed in Table 1. The average particle size of AgNPs was observed to be $18.31 \mathrm{~nm}$. Similar particle size was found by Gulbagca et al. of $19.75 \mathrm{~nm}$ [21]. The highest peak at $2 \theta=$ $38.5^{\circ}$ matching to spherical nanoparticles crystallized in the FCC structure with (111) lattice plane [22].

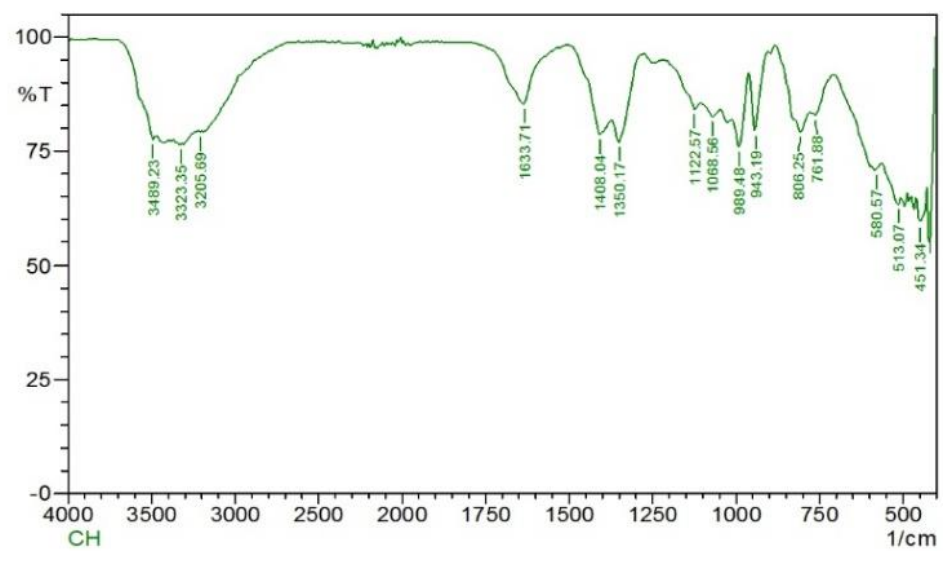

Figure 2. FTIR of dried silver nanoparticles.

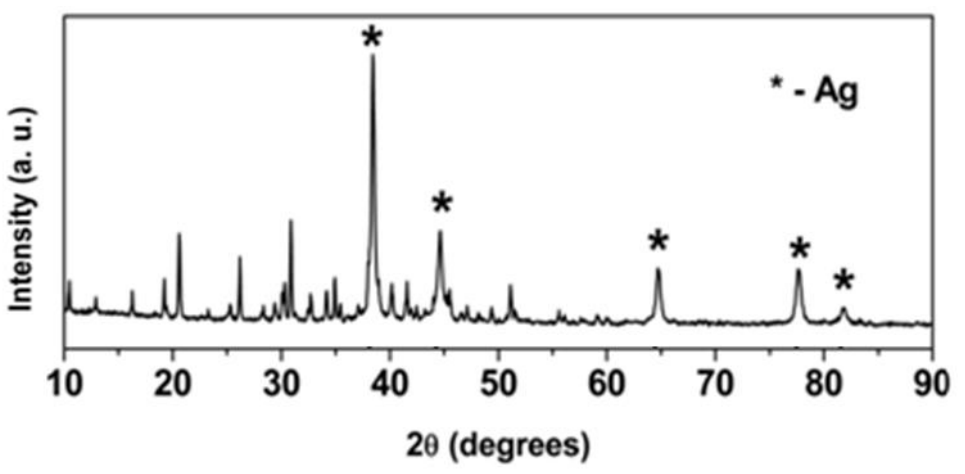

Figure 3. XRD image of dried silver nanoparticles.

Table 1. Calculation of particle size of silver nanoparticles.

\begin{tabular}{l|l|l|l|l}
\hline \multicolumn{1}{c|}{ S.No } & \multicolumn{1}{|c|}{$\mathbf{\theta}$} & \multicolumn{1}{|c|}{ d (ang) } & \multicolumn{1}{|c}{ FWHM (ang) } & D(nm) \\
\hline $\mathbf{1}$ & 38.451 & 2.339 & 0.345 & $\mathbf{2 4 . 4 0}$ \\
\hline $\mathbf{2}$ & 44.676 & 2.027 & 0.433 & $\mathbf{2 2 . 0 5}$ \\
\hline $\mathbf{3}$ & 64.762 & 1.438 & 0.534 & $\mathbf{1 7 . 6 2}$ \\
\hline $\mathbf{4}$ & 77.699 & 1.228 & 0.580 & $\mathbf{1 7 . 6 0}$ \\
\hline $\mathbf{5}$ & 81.881 & 1.1715 & 1.062 & $\mathbf{9 . 9 1}$ \\
\hline \multicolumn{7}{l}{ The average value of the crystalline size of nanoparticles of silver } & $\mathbf{1 8 . 3 1}$
\end{tabular}




\subsection{TEM and EDS analysis.}

Figure 4 ( $a$ and $b$ ) shows the morphology and size of the particles analyzed using a highresolution transmission electron microscope.
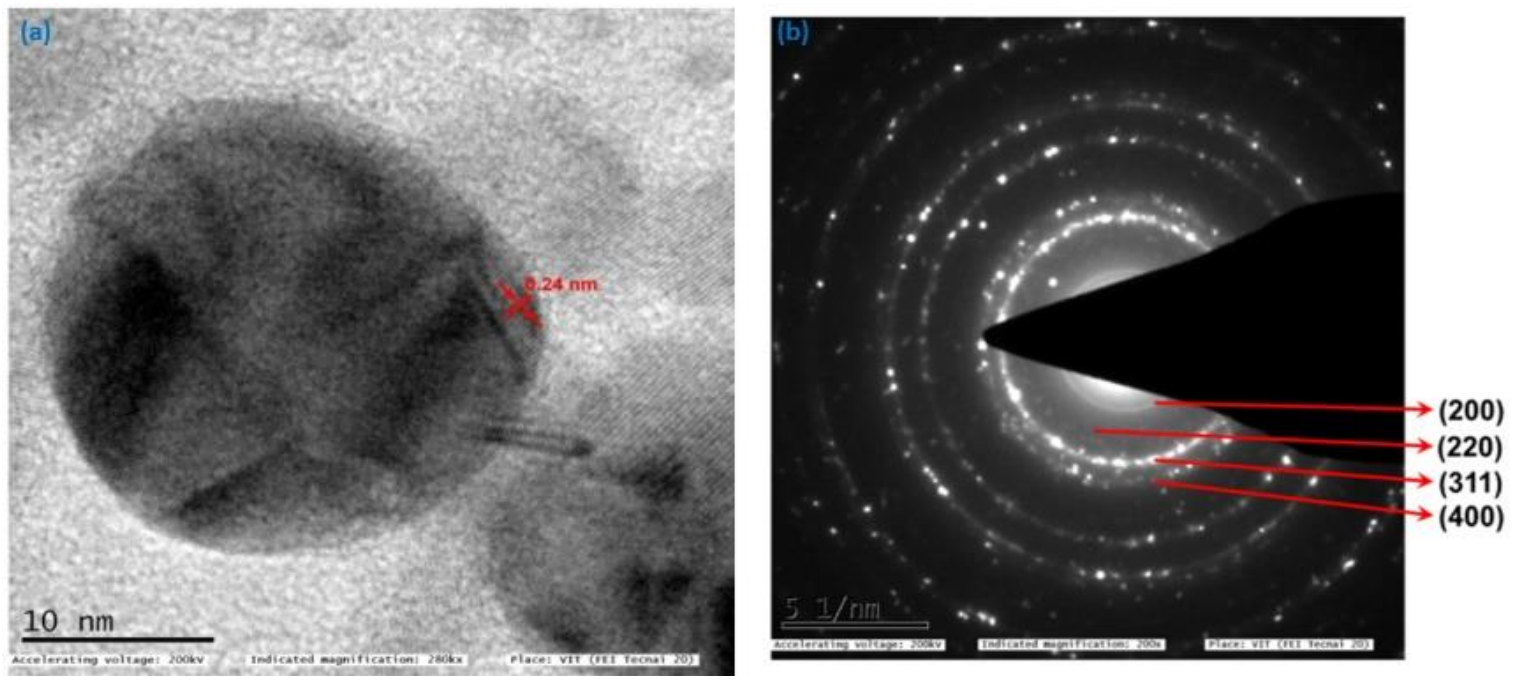

Figure 4. HRTEM Micrograph (a) Image showing d spacing (b) SAED pattern of Ag nanoparticle.

Table 2. Zones of Inhibition at various concentration.

\begin{tabular}{|c|c|c|c|c|c|c|}
\hline \multirow[t]{3}{*}{ S.No } & \multirow{3}{*}{$\begin{array}{c}\text { Name of the } \\
\text { Microorganism }\end{array}$} & \multicolumn{5}{|c|}{ Zone of inhibition ( $\mathrm{mm}$ in diameter) } \\
\hline & & \multirow{2}{*}{$\begin{array}{c}\text { PositiveControl } \\
\text { (Tetracycline } 30 \\
\mu \mathrm{g})\end{array}$} & \multicolumn{4}{|c|}{ Samples $(\mu \mathrm{g})$} \\
\hline & & & 25 & 50 & 75 & 100 \\
\hline 1 & Bacillus subtilis & $21 \pm 5$ & $2 \pm 5 \mathrm{~mm}$ & $5 \pm 5 \mathrm{~mm}$ & $10 \pm 5 \mathrm{~mm}$ & $14 \pm 5 \mathrm{~mm}$ \\
\hline 2 & $\begin{array}{l}\text { Pseudomonas } \\
\text { aeruginosa }\end{array}$ & $16 \pm 5$ & R & $5 \pm 5 \mathrm{~mm}$ & $8 \pm 5 \mathrm{~mm}$ & $12 \pm 5 \mathrm{~mm}$ \\
\hline
\end{tabular}

(a)
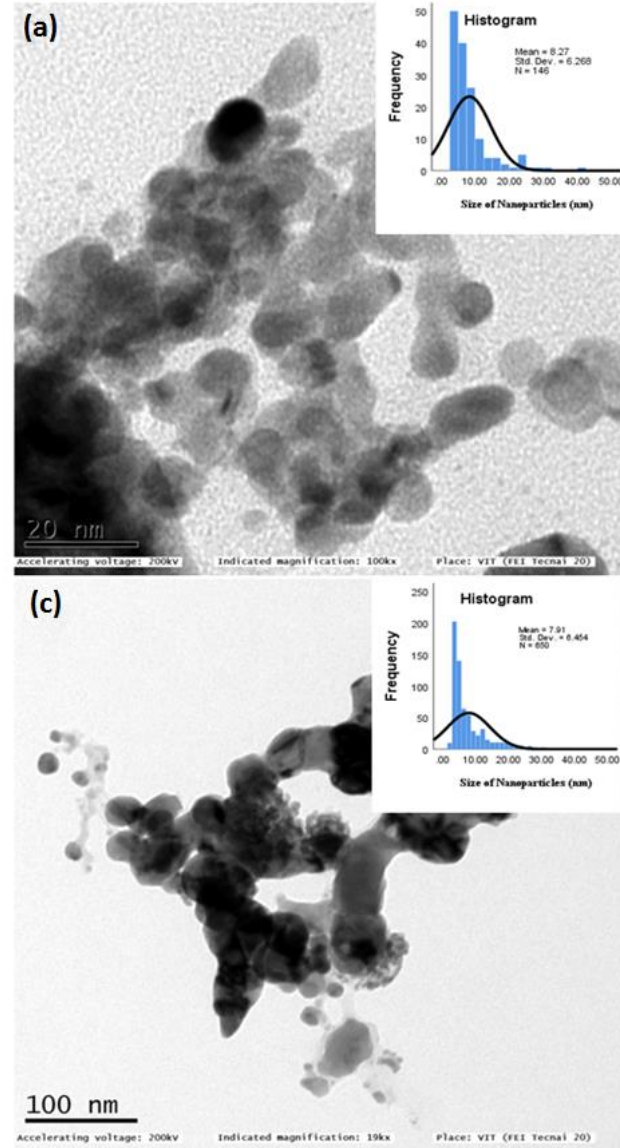

(b)
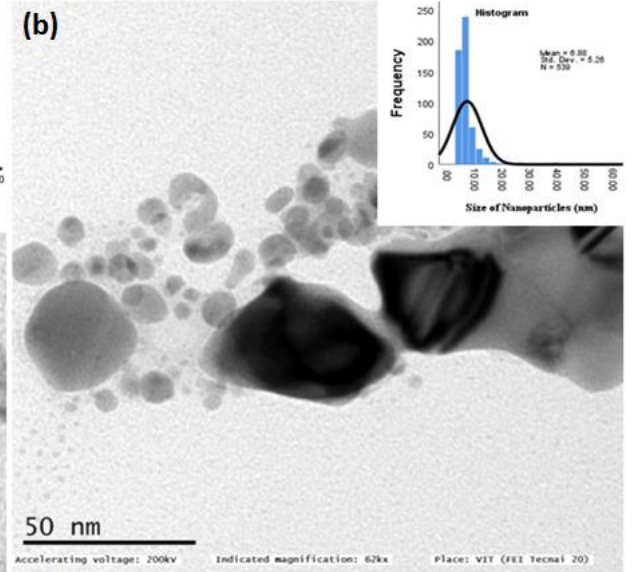

(d)

Figure 5. TEM micrograph of silver nanoparticle. 
The selected area electron diffraction (SAED) pattern shows the ring-like diffraction pattern, which indicates that the particles are crystalline. The diffraction rings may be indexed based on the fcc structure of silver. The four rings formed due to reflections from (200), (220), (311) and (400) lattice planes of fcc silver, respectively. A similar SAED pattern was obtained with silver nanoparticles synthesized by song et al. [6]. Figure 5 (a to d) shows TEM micrograph of silver nanoparticles at $20 \mathrm{~nm}, 50 \mathrm{~nm}, 100 \mathrm{~nm}, 200 \mathrm{~nm}$. It was observed that the particle size with variable shape. However, most of them showed spherical shape in nature with some triangular morphology. The majority of the nanoparticles were observed to be scattered with few of them showing aggregates of different sizes as observed under TEM micrograph. Image $\mathbf{J}$ software was used to estimate the particle sizes. The data obtained were used to draw the frequency distribution histogram using IBM statistics software. The particles are nearly spherical nature with a particle size of $8 \pm 3.05 \mathrm{~nm}$. The HRTEM image used to determine the fringe width or interplanar spacing and was found to be $0.221 \mathrm{~nm}$. EDS analysis confirms the formation of the silver particle, as shown in Figure 6.

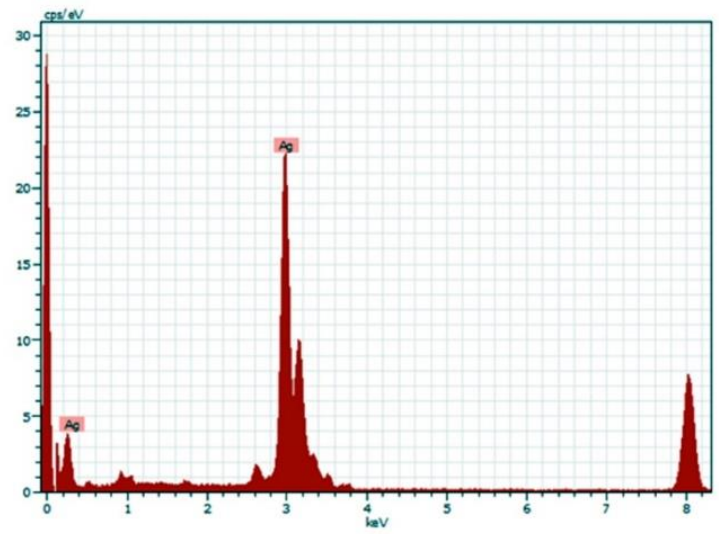

Figure 6. EDS analysis of silver particle.
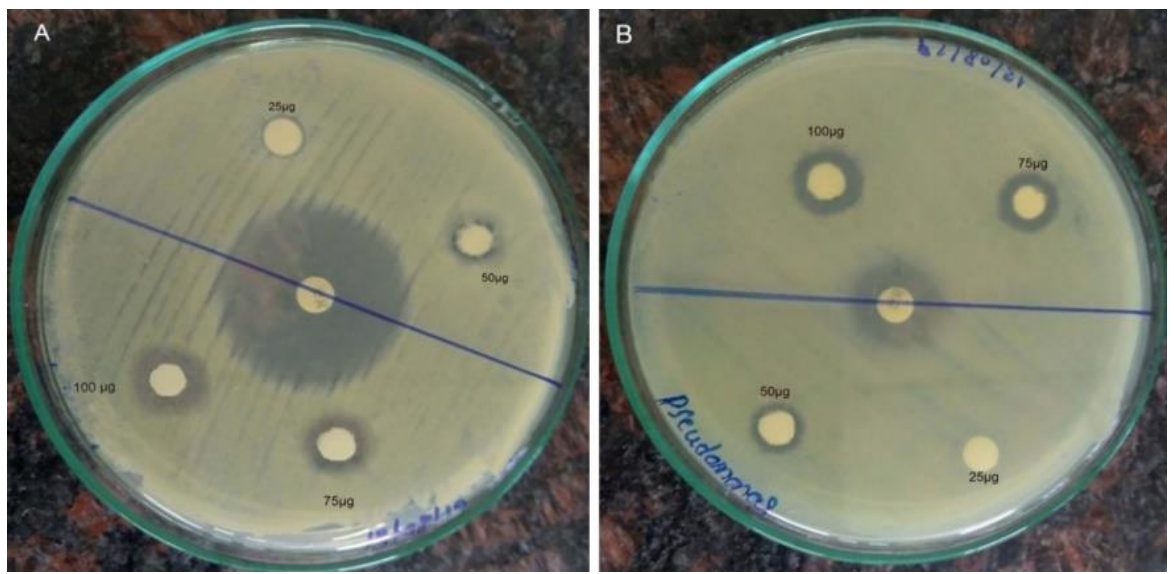

Figure.7. AgNPs showing antibacterial activity against human pathogenic: (a) Bacillus subtilis; (b) Pseudomonas aeruginosa.

\subsection{Antibacterial activity.}

Figure 7 shows the disc diffusion method confirms the antibacterial activity of the AgNPs. The inhibition zones found out to be of a maximum value of $19 \mathrm{~mm}$ and $17 \mathrm{~mm}$ against the bacteria's Bacillus subtilis and Pseudomonas aeruginosa, respectively. The values tabulated in Table 2. The agar well diffusion method conforms to the antibacterial activity of the AgNPs synthesized using $\mathrm{NaBH}_{4}$ against the bacterial strains [23]. Guzman et al. reported the size of silver nanoparticles also affects the inhibition to a greater extent [1]. It was observed that the 
decrease in particle size shows lower resistance against the microbial activity. The spherical shape of nanoparticle observed in TEM analysis has influenced the antimicrobial properties. In this analysis, Pseudomonas aeruginosa shows better antimicrobial properties as compared to Bacillus subtilis. Similar results were observed by Xuan et al. In his observation AgNPs exhibited a zone of inhibition of $10 \mathrm{~mm}$ against Escherichia coli and $7 \mathrm{~mm}$ against Staphylococcus aureus bacteria [24].

\section{Conclusions}

In this study, the AgNPs were successfully synthesized by using the chemical method. The characterization of the synthesized silver nanoparticles carried out by employing XRD, HRTEM, FTIR, and EDX, X-Ray diffraction, and HRTEM revealed the amorphous and crystalline nature of the AgNPs. The X-Ray diffraction implied the average crystalline size of $18.31 \mathrm{~nm}$ as calculated by employing the Debye-Scherrer formula. HRTEM also implied the formation of AgNPs particle size range of $8 \mathrm{~nm} \pm 3.05 \mathrm{~nm}$. EDX analysis confirms the $\mathrm{Ag}$ peak. AgNPs here exhibited acceptable zones of inhibition against Bacillus subtilis and Pseudomonas aeruginosa bacteria. Thus the research implies that chemical synthesis of AgNPs using Sodium borohydride and ethanol can be used as methods for preparing silver nanoparticles.

\section{Funding}

There is no external funding involved in the preparation of this article.

\section{Acknowledgments}

The authors are thankful to the School of Advanced Science (SAS), Vellore Institute of Technology, Vellore Campus, for using the HRTEM facility for characterization of the AgNPs synthesized in this research. Avanz Bio Lab, Chennai, for performing the antibacterial activity test of the AgNPs synthesized in the research.

\section{Conflicts of Interest}

The authors declare no conflict of interest.

\section{References}

1. Murugan, N.; Natarajan, D. Bionanomedicine for antimicrobial therapy - a case study from Glycosmis pentaphylla plant mediated silver nanoparticles for control of multidrug resistant bacteria. Lett. Appl. NanoBioScience 2018, 8, 523-540. https://doi.org/10.33263/LIANBS834.523540

2. Ruddaraju, L.K.; Pallela, P.N.V.K.; Pammi, S.V.N.; Padavala, V.S.; Kolapalli, V.R.M. Synergetic antibacterial and anticarcinogenic effects of Annona squamosa leaf extract mediated silver nano particles. Materials Science in Semiconductor Processing 2019, 100, 301-309, https://doi.org/10.1016/j.mssp.2019.05.007.

3. Nakamura, S.; Sato, M.; Sato, Y.; Ando, N.; Takayama, T.; Fujita, M.; Ishihara, M. Synthesis and Application of Silver Nanoparticles (Ag NPs) for the Prevention of Infection in Healthcare Workers. International Journal of Molecular Sciences 2019, 20, 135-140, https://doi.org/10.3390/ijms20153620.

4. Ahmad, M.B. Synthesis and characterization of silver/talc nanocomposites using the wet chemical reduction method. Int J Nanomedicine 2010, 5, 743-751, https://doi.org/10.2147/IJN.S13227.

5. [Badi'ah, H.I.; Seedeh, F.; Supriyanto, G.; Zaidan, A.H. Synthesis of Silver Nanoparticles and the Development in Analysis Method. IOP Conference Series: Earth and Environmental Science 2019, 217, 18, https://doi.org/10.1088/1755-1315/217/1/012005.

6. Song, J.Y.; Kim, B.S. Rapid biological synthesis of silver nanoparticles using plant leaf extracts. Bioprocess 
and Biosystems Engineering 2008, 32, 79-84, $\quad$ https://doi.org/10.1007/s00449-008-0224-6.

7. Malina, D.; Sobczak-Kupiec, A.; Wzorek, Z.; Kowalski, Z. Silver nanoparticles synthesis with different concentrations of polyvinylpyrrolidone. Digest Journal of Nanomaterials and Biostructures 2012, 7, 15271534.

8. Hamouda, R.A.; Hussein, M.H.; Abo-elmagd, R.A.; Bawazir, S.S. Synthesis and biological characterization of silver nanoparticles derived from the cyanobacterium Oscillatoria limnetica. Scientific Reports 2019, 9 , 1-17, https://doi.org/10.1038/s41598-019-49444-y.

9. Bahlol, S.H.; Foda, F.M.; Ma, J.; Han, H. Robust Synthesis of Size-Dispersal Triangular Silver Nanoprisms via Chemical Reduction Route and Their Cytotoxicity. Nanomaterials 2019, 9, 1-14, https://doi.org/10.3390/nano9050674.

10. Alshareef, A.; Laird, K.; Cross, R.B.M. Shape-dependent antibacterial activity of silver nanoparticles on Escherichia coli and Enterococcus faecium bacterium. Applied Surface Science 2017, 424, 310-315, https://doi.org/10.1016/j.apsusc.2017.03.176.

11. Mavani, K.; Shah, M. Synthesis of Silver Nanoparticles by using Sodium Borohydride as a Reducing Agent. IJERT 2013, 2, 1-5, https://doi.org/10.13140/2.1.3116.8648

12. Song, K.C.; Lee, S.M.; Park, T.S.; Lee, B.S. Preparation of colloidal silver nanoparticles by chemical reduction method. Korean Journal of Chemical Engineering 2009, 26, 153-155, https://doi.org/10.1007/s11814-009-0024-y.

13. Gao, M.; Sun, L.; Wang, Z.; Zhao, Y. Controlled synthesis of Ag nanoparticles with different morphologies and their antibacterial properties. Materials Science and Engineering: C 2013, 33, 397-404, https://doi.org/10.1016/j.msec.2012.09.005.

14. Ahmed, S.; Saifullah; Ahmad, M.; Swami, B.L.; Ikram, S. Green synthesis of silver nanoparticles using Azadirachta indica aqueous leaf extract. Journal of Radiation Research and 2016, 9, 1-7, https://doi.org/10.1016/j.jrras.2015.06.006.

15. Jyoti, K.; Baunthiyal, M.; Singh, A. Characterization of silver nanoparticles synthesized using Urtica dioica Linn. leaves and their synergistic effects with antibiotics. Journal of Radiation Research and Applied Sciences 2016, 9, 217-227, https://doi.org/10.1016/j.jrras.2015.10.002.

16. Mostafa, A.A.; Al-Askar, A.A.; Almaary, K.S.; Dawoud, T.M.; Sholkamy, E.N.; Bakri, M.M. Antimicrobial activity of some plant extracts against bacterial strains causing food poisoning diseases. Saudi Journal of Biological Sciences 2018, 25, 361-366, https://doi.org/10.1016/j.sjbs.2017.02.004.

17. Ibrahim, H.M.M. Green synthesis and characterization of silver nanoparticles using banana peel extract and their antimicrobial activity against representative microorganisms. Journal of Radiation Research and Applied Sciences 2015, 8, 265-275, https://doi.org/10.1016/j.jrras.2015.01.007.

18. Vigneshwaran, N.; Ashtaputre, N.M.; Varadarajan, P.V.; Nachane, R.P.; Paralikar, K.M.; Balasubramanya, R.H. Biological synthesis of silver nanoparticles using the fungus Aspergillus flavus. Materials Letters 2007, 61, 1413-1418, https://doi.org/10.1016/j.matlet.2006.07.042.

19. Dorobantu, L.S.; Goss, G.G.; Burrell, R.E. Effect of light on physicochemical and biological properties of nanocrystalline silver dressings. RSC Advances 2015, 5, 14294-14304, https://doi.org/10.1039/C4RA15745A.

20. Kosmala, A.; Wright, R.; Zhang, Q.; Kirby, P. Synthesis of silver nano particles and fabrication of aqueous $\mathrm{Ag}$ inks for inkjet printing. Materials Chemistry and Physics 2011, 129, 1075-1080, https://doi.org/10.1016/j.matchemphys.2011.05.064.

21. 21. Gulbagca, F.; Ozdemir, S.; Gulcan, M.; Sen, F. Synthesis and characterization of Rosa canina mediated biogenic silver nanoparticles for anti-oxidant, antibacterial, antifungal, and DNA cleavage activities. Heliyon 2019, 5, https://doi.org/10.1016/j.heliyon.2019.e02980.

22. Raza, A.M.; Kanwal, Z.; Rauf, A.; Sabri, N.A.; Riaz, S.; Naseem, S. Size- and Shape-Dependent Antibacterial Studies of Silver Nanoparticles Synthesized by Wet Chemical Routes. Nanomaterials 2016, 6, 1-15, https://doi.org/10.3390/nano6040074.

23. Kumar, V.; Wadhwa, R.; Kumar, N.; Maurya, P.K. A comparative study of chemically synthesized and Camellia sinensis leaf extract-mediated silver nanoparticles. 3 Biotech 2019, 9, 1-9, https://doi.org/10.1007/s13205-018-1544-0.

24. Vu, X.H.; Duong, T.T.T.; Pham, T.T.H.; Trinh, D.K.; Nguyen, X.H.; Dang, V.-S. Synthesis and study of silver nanoparticles for antibacterial activity against Escherichia coli and Staphylococcus aureus. Advances in Natural Sciences: Nanoscience and Nanotechnology 2018, 9, https://doi.org/10.1088/2043-6254/aac58f. 